\title{
The Effect of Using Blended Learning Method on Learning Motivation Among Students at the Department of Psychological Counselling in Jadara University
}

\author{
Associate Professor Kamal Sobhi Nazzal \\ Assistant Professor Mohammad Nasser Alradi
}

\begin{abstract}
This study aimed to identify the effect of using the blended learning method on learning motivation among students at the Department of Psychological Counselling in Jadara University and its relationship to the variables, teaching methods, and the learning motivation. It also aimed to identify the extent of using e-learning methods in increasing students' motivation towards learning. To achieve the objectives of this study, the researchers made a semiexperimental study on a representative sample from Jadara University that consisted of (137) students from the College of Educational Sciences -Psychological Counselling. The researchers designed a scale to gauge the learning motivation among an exploratory sample. The scale consisted of (36) items distributed over six areas, which are: inclination, warmth, social, competence, obedience, and responsibility. The results showed an apparent variation between the averages of the experimental and control groups' responses on each of the areas of the learning motivation scale according to the variable teaching methods. The results also showed that there were statistically significant differences at the level of statistical significance $(\alpha \leq 0.05)$ between the estimates of the experimental and control groups on each area of the motivation scale due to the effect of the teaching methods and in favor of the experimental group that was taught by using blended learning. The validity and reliability of the learning motivation scale were checked.
\end{abstract}

DOI: $10.7176 / \mathrm{JEP} / 11-15-05$

Publication date:May $31^{\text {st }} 2020$

\section{Introduction}

Over the past few years, the enormous scientific and technological progress has led to great changes in the lifestyle of humans. As a result of these changes, this period has witnessed the use of technology in various fields, and it has been called the age of electronic technology, the period of digital technology, the age of communication and IT. These changes have brought a major turn in the field of education in terms of its goals, teaching process and the emergence of modern learning methods including e-learning, direct and indirect learning, distance learning and mobile learning. All these teaching forms require using information technology in the teaching and learning process.

Motivation in the era of information technology is considered a source of human energy and the basis for forming habits; attitudes, and practices among individuals since the traditional methods of learning and teaching can no longer achieve the new goals. Accordingly, the roles of the teacher have changed and taken new dimensions to modify the behavior of learners and stimulate his motivation in a way that is consistent with new harmonious goals in the era of electronic information technology. One of the most important goals that the educational process aims to achieve for the learners in this era is providing them with the basic and necessary skills such as creative thinking, problem-solving and decision-making. These skills have become the core of the educational process because it prepares learners to adapt to the rapidly changing society that is characterized by its huge-changing quantity of knowledge.

One of the most important requirements of this era is the existence of a learner who has the ability to pursuit self-learning; has the desire, tendencies and internal motivation that is provided by the technological educational environment to motivate and urge the learner to learn and continue with it, as this kind of learning does not require a specific time for learning, going to school or university instead it enables the learner to learn at any time and under any circumstance as long as he can deal with electronic technology and has the motivation to learn beyond time and space.

\section{Study problem and questions.}

Students face many obstacles and academic difficulties in their university, and some of these difficulties are related to their motivation to attend regularly and to follow the content and academic activities within the lecture halls. To increase students' motivation the researchers used e-learning (blended learning) as a new learning style at the university, where knowledge and skills content were presented in an attractive and enjoyable way. This study attempts to show the extent to which e-learning methods are used and their impact on students 'motivation towards the use of digital education technology, specifically answering the following two questions:

1.What is the effect of using blended learning approach on the learning among students of the Department 
of Psychological Counseling at Jadara University?

2. Are there statistically significant differences at the level of statistical significance $(\alpha \leq 0.05)$ for the effect of usingblended learning on the learning motivation among students of the Department of Psychological Counseling at Jadara University due to teaching methods ( blended and traditional learning)?

\section{The importance of the study}

The importance of this study lies in identifying the most significant programs and technological means most used by university students, as well as showing the impact of using these programs and the electronic means on the student's motivation towards e-learning. As e-learning contributes greatly in all components of the educational and training process, and it has become an important hub in many western universities. E-learning has contributed to increasing the attractiveness and quality of education, as it uses communication systems that students prefer including audio, visual, and sensory. It is often considered an acceptable way for students who have a job or are suffering from mental or psychological problems such as being introverted and embarrassed.The findings of this study can contribute to helping decision-makers develop their educational plans and programs to fit university education. This study aims to identify the impact of e-learning (blended education) on students' motivation, in order to broaden the generalization of its results and expand its use and application in all educational institutions as well as providing a source of information for researchers in the field of e-learning by providing appropriate educational literature.

\section{The study limits}

The study is limited to:

Time Limits: The first semester of the school academic year (2019/2020).

Spatial limits: Jadara University / College of Educational Sciences.

Human limits: A sample of students from educational counseling College.

\section{Definitions:}

E-learning:Nehme (2010) defines e-learning as technology-supported education. Where Al Jabari(2011) defines it as a method of teaching depends on the use of modern means of communication from computers, networks and multimedia, including sound, image, graphics, search engines and electronic libraries, whether it is remotely or in the classroom. briefly, it is the use of technology of all kinds to communicate information to the learner with the shortest time, less effort and the greatest benefit.

E-learning adopted from its various online sources tools to enhance the educational process, including the use of the internet within the classroom to link students to teachers called online classrooms or to link them remotely for science research purposes, collaborative studies and follow-up, and the creation of virtual electronic classrooms across local networks. Within this study, e-learning involves any learning that takes place through the use of digital devices and technology, either directly (ON-LINE) or through local and global networks, as well as the use of mobile within learning process and learning management systems such as B.b or Moodel, social networks, search engines and educational apps.

Motivation towards e-learning:Ghergulescu \& Muntean (2010) see motivation as incentive (representing a psychological trait) or energy to achieve the goal of achieving knowledge and maintaining participation in the learning process.

Al-Issawi (2011) points out that behavioral motivation is the learner's internal or external state that drives his behavior, performance, persistence and points him to the target. While the cognitive motivation is an internal state that stimulates the learner's ideas and knowledge as well as raising his awareness and interests, as it urges him to persist his performance to reach a state of knowledge and psychological balance. On the humanitarian side, it is an internal enthusiasm that motivates the learner to maximize his full potential in any educational situation aimed at satisfying his desires and achieving himself.

Procedural definition:It is the responses of acceptance or rejection (support or opposition) for students towards learning through technological applications and computer software that is considered a model for e-learning and is measured by the total degrees obtained by the student's responses to the items of the scale prepared by the researchers for this purpose.

\section{Literature review and previous studies}

Nehme (2010) defines e-learning as technology-supported education. Al-Shannaq and Bani Dhoumi (2010) defines electronic learning procedurally as students learning through using various electronic media such as CDs, floppies, using computers, Internet and local networks (LAN) by adopting the principle of Self-taught or teacherassisted learning, as well as using the data show.Wu and Hwang (2010) believe that e-learning has the same ability to transfer knowledge and develop the learning process as traditional teaching does. They also believe that learning is no longer limited to the traditional way of teaching or regular classes since e-learning and technology provide 
powerful means to support learning, especially with the accelerated technological developments and the Internet that plays a major role in providing learning resources.

Nehme (2010) sees that e-learning is a general concept that has several teaching aspects, and it implements educational methods through using networks, internet, formal and informal tasks that are supported by learners' interaction and cooperation through information technology. Keller (2008) believes that using assistive technology in the learning process is increasing rapidly as there are different kinds of e-learning such as blended learning, direct-learning (On-line) and mobile learning (M-learning).

Nehme (2010) states that some of the classes that are taught entirely through direct learning are called technological direct classes, while the classes in which education is combined between traditional education based on the interaction between the teacher and the student and e-learning are called blended classes, where the traditional and technological educationare integrated.

Miqdad (2010) notes that one of the characteristics of e-learning, such as distance learning characteristics, is that there is a separation between teacher and learner, that it is a focused-learner process, and that learning is the responsibility of the learner.And the learning that takes place throughout the different stages of life the so-called continuing education, and moreover E-learning is characterized using digital technology, it depends seriously on modern technology, especially computer technology, communication technology, and the Internet.E-learning seeks to achieve interaction, whether between the student and the teacher or between the student and other students. This interaction has become possible due to advancement and its degree differs according to the extent of the use of information technology media. E-learning and using information technology is one of the means of education that may solve a set of problems depending on the method used for its application and therefore several studies were conducted on this area, its results varied and most of them focused on the method of employing information technology in the teaching process as well as the subject taught.

Keller (2008) believes that despite the benefits of e-learning, it is still not clear how to define it clearly in the educational system or how to use it, as it is necessary to know the precise characters of the technological learning environment and to define its effective features and how it motivates student's learning.Designing a technological learning environment is completely different from the traditional education environment and one of the most important factors that must be considered when using technological learning is the student's learning motivation. (2008, Keller) believes that most learning environments now employ technology to aid learning and education, some of which are self-directed which is internally motivated by the learner, while the other is directed by the teacher.

Hartnett et al. (2011) state that motivation is the process directed at motivating the learner and increasing his activity as motivation affects what we learn, how we learn, when and how we choose to learn. Brophy (2010) states that contemporary perspectives link motivation with the learner's thinking capabilities, emotional processes, ideas, beliefs, goals, aspirations, situations, and the interactive relationship between the learner and the environment.

Miqdad (2010) thinks that increasing learning motivation in the e-learning environment differs from the regular education situation where it focuses on one part of the educational process that is the learner alone, and this does not apply to the e-learning situations. Consequently, the strategy of increasing motivation in the normal learning situation is not necessarily effective in increasing learners' motivation and differ from those in e-learning situations. For this, it is necessary to think of other strategies that are appropriate for e-learning.

Hartnett et al. (2011) explains that research that has addressed motivation in e-learning environments has two trends; the first based on a model in features that sees motivation as a feature or characteristic of the learner's personality, and that the learner in the e-learning environment in general has a fundamental motivation. While the other trend believes that it is necessary to design an e-learning environment in order to support and increase the learner's motivation.Research has shown that learners who are motivated to learn are more fortunate in logical linking and listening, adopting a deep approach to learning, improving performance, and stimulating creativity and perseverance to integrate into educational activities.Among the studies that addressed the topics of e-learning and the motivation towards the process of e-learning are the following: Al-Nqithan (2009) conducted a study on the effect of using PP software, which is an interactive computer program, in explaining the motivation towards learning. The indicated that the employment of this software increases motivation towards learning.

In a theoretical study conducted by (Miqdad, 2010) on the motivation to learning among students who learn by e-learning, the researcher explained the difference between the motivation in the traditional situation and the motivation towards learning in the e-learning situations. The researcher stated that the strategies to increase motivation in normal learning situations are not necessarily effective in increasing the learner's motivation in elearning situations, and it is necessary to find more suitable strategies for e-learning, including the model of attention, relevance, confidence, and satisfaction.

Nehme (2010) conducted a study on university students that dealt with controlling the educational environment through a program such as Webct and $\mathrm{Bb}$ and others, the study concluded that professors who use (IT) emphasize important points that must be taken into account during the implementation and adaptation of the 
educational environment and the most important point is increasing motivation and reinforcement among students. The study also showed that student's motivation and educational performance increased when the interaction between the student and the teacher was increased because the student's discipline reduces his anxiety and tension.

Kim \& Frick (2011) investigated the factors that stimulate learner's motivation in direct self-learning and examines the level of learner's motivation and how this level changes during the courses. It also aimed to identify the factors associated with changing learner's motivation. The study concluded that there are four basic factors that influence the learner's motivation: attention, awareness of the importance of learning, self-confidence, and satisfaction, and the association of these factors with direct self-learning will enable the learner to achieve the learning goals successfully. The study also concluded that the student's motivation and more satisfaction increased with direct self-education when the content is relevant to the learner's life. The student's ease of dealing with technology, the students' enthusiasm for continuous self-learning and their conviction that it is their right, as well as providing encouragement and affirmation at the beginning and during the educational material.

Hartnett et al. (2011) examines the motivation of pre-service teachers in New Zealand who were given two different topics in a direct learning environment (On-line). The study in its first stage raises a question about the nature of the motivation towards learning in the direct learning environment which led to the next stage of the study by taking two samples from the examinees. The researchers used the case study method and several measurement methods to determine the nature of motivation. The study concluded that the motivation towards learning is a complex and interrelated process and that learners in the direct learning environment were not driven by internal motivation as mentioned in the studies in this field. The factors of the educational situations must be considered during designing the learning environment, setting goals, and the learners should be given the opportunity to discuss and choose what is appropriate to them to find a motive towards remaining the learning process.

\section{Study methodology and procedures}

The researchers used the quasi-experimental method by randomly selecting study participants to reveal the effect of blended education on the learning motivation among Jadara University Department of Psychological Counseling students. The study was applied to two groups: experimental and control. The differences between the averages of learning motivation of the two groups were examined.

\section{Study sample}

The study sample comprised of (137) male and female students who are studying an introductory course in psychology, distributed on two divisions, during the second semester of the academic year 2018/2019, at the University of Jadara. The two divisions were randomly divided into two groups, the first group: an experimental group of (75) students who were taught according to blended learningand the control group that was taught using the traditional way and it consisted of (62) students.

Study tool: The researchers designed the learning motivation scale which consists of (36) items distributed equally across six areas, which are: inclination, warmth, social, competency, obedience, and responsibility.

Scale validity: To check the validity of the scale, the researchers presented it to a committee of (8) arbitrators who are qualified and experienced from the academic staff in colleges of education. The arbitrators' advice and suggestions were considered such as the linguistic wording of some paragraphs.

Scale reliability: To check the reliability of the scale, the researchers calculated the reliability coefficients in two ways: The first is the method of the test re-test, where the researchers applied it to an exploratory sample of (33) students from outside the study sample by applying it twice and with a time interval between the first application and the second of two weeks.Pearson correlation coefficients were calculated between the results of the two tests, where the reliability coefficients ranged between $(0.80-0.91)$, and the correlation coefficient value for the total scale was (0.91). As for the second method, the Cronbach alpha method was used to identify the consistency of the items, the values of the reliability coefficients of the areas ranged between $(0.84-0.93)$ and (0.92) for the whole scale, these values are acceptable for conducting such a study.

Equivalence of the two study groups: To check the equivalence of the two study groups, the researchers applied the learning motivation scale to the members of the experimental and control groups, before starting teaching, the means and the standard deviations for the estimates of the members of the experimental and control groups were calculated on each of the areas of the learning motivation scale in the pre-test, according to the method of teaching (blended learning or the traditional way) as shown in Table (1). 
Table (1): Means and SD for the estimates of the experimental and control groups in the areas of scale in the pretest.

\begin{tabular}{|c|c|c|c|}
\hline Areas & Groups & Means * & SD \\
\hline \multirow{2}{*}{ Inclination } & control & 3.12 & .67 \\
\hline & experimental & 3.16 & .98 \\
\hline \multirow{2}{*}{ Warmth } & control & 3.28 & .73 \\
\hline & experimental & 3.24 & .77 \\
\hline \multirow{2}{*}{ Social } & control & 3.31 & .75 \\
\hline & experimental & 3.28 & .72 \\
\hline \multirow{2}{*}{ Competence } & control & 3.39 & .60 \\
\hline & experimental & 3.34 & .67 \\
\hline \multirow{2}{*}{ Obedience } & control & 3.16 & .98 \\
\hline & experimental & 3.11 & .73 \\
\hline \multirow{2}{*}{ Responsibility } & control & 3.36 & .77 \\
\hline & experimental & 3.30 & .75 \\
\hline \multirow{2}{*}{ Total } & control & 3.26 & .51 \\
\hline & experimental & 3.24 & .53 \\
\hline
\end{tabular}

- The highest degree is(5).

Table (1) indicates that there are no differences between the means for the estimates of the experimental and control groups, on each of the areas of the learning motivation scale due to the variable method of teaching. To identify the levels of statistical significance, a test $(\mathrm{T})$ was used for the independent samples as shown in Table (2).

Table (2): Results of the (T) test for independent samples of the differences between the estimates of the experimental and control groups in each of the areas of the learning motivation scale due to the variable method of teaching.

\begin{tabular}{|c|c|c|c|c|c|c|}
\hline Areas & Group & *Means & SD & FD & T value & $P$ value \\
\hline \multirow{2}{*}{ Inclination } & control & 3.12 & .67 & \multirow{2}{*}{135} & \multirow{2}{*}{0.273} & \multirow[t]{2}{*}{0.841} \\
\hline & experimental & 3.16 & .98 & & & \\
\hline \multirow{2}{*}{ Warmth } & control & 3.28 & .73 & \multirow{2}{*}{135} & \multirow{2}{*}{0.309} & \multirow{2}{*}{0.768} \\
\hline & experimental & 3.24 & .77 & & & \\
\hline \multirow{2}{*}{ Social } & control & 3.31 & .75 & \multirow{2}{*}{135} & \multirow{2}{*}{0.238} & \multirow{2}{*}{0.894} \\
\hline & experimental & 3.28 & .72 & & & \\
\hline \multirow{2}{*}{ Competence } & control & 3.39 & .60 & \multirow{2}{*}{135} & \multirow{2}{*}{0.455} & \multirow{2}{*}{0.517} \\
\hline & experimental & 3.34 & .67 & & & \\
\hline \multirow{2}{*}{ Obedience } & control & 3.16 & .98 & \multirow{2}{*}{135} & \multirow{2}{*}{0.341} & \multirow{2}{*}{0.621} \\
\hline & experimental & 3.11 & .73 & & & \\
\hline \multirow{2}{*}{ Responsibility } & control & 3.36 & .77 & \multirow{2}{*}{135} & \multirow{2}{*}{0.460} & \multirow{2}{*}{0.507} \\
\hline & experimental & 3.30 & .75 & & & \\
\hline \multirow{2}{*}{ Total } & control & 3.26 & .51 & \multirow{2}{*}{135} & \multirow{2}{*}{0.223} & \multirow{2}{*}{0.910} \\
\hline & experimental & 3.24 & .53 & & & \\
\hline
\end{tabular}

Table (2) shows that there are no statistically significant differences at the level of significance $(\alpha \leq 0.05)$ between the means of the experimental and control groups estimation on each of the areas of the learning motivation scale that due to the variable " method of teaching" in the pre-test. This means that the two study groups before the application of the education process are equivalent.

Study procedures:

Study procedures: The researchers followed these procedures:

1 .Reviewing theoretical literature and previous studies that addressed blended education and learning motivation, and then an arbitrated scale including items measuring learning motivation was designed and established .

2 .The validity and reliability of the scale were checked.

3 .Taking the approval of the competent authorities to facilitate the implementation of the study.

4 .Determining the study sample.

5. Choosing the curriculum that will be taught using the blended learning method and the traditional method.

Study variables:

The study included the following variables:

1. Independent variable :

A- The blended learning program that was used to teach the experimental group. 
B- The traditional method that was used to the control group.

2. Dependent variable:Learning motivation: expressed by the arithmetic mean of students' grades on the learning motivation scale.

Statistical treatments:To answer the questions of the study, the researchers followed these statistical treatments: 1 Means and standard deviations.

2A t-test was used to check if the averages of the two study samples were equal.

3ANCOVA

4MANCOVA.

\section{Results}

To answer the study question, Mean and standard deviations of the responses of the experimental and control groups were calculated, on each area of the scale, according to the variable of the method of teaching. The researchers used the analysis (MANCOVA). Table (3) shows the arithmetic averages and the standard deviations of the experimental and control groups' responses, on each of the areas of the scale in the pre and post-test, according to the method of teaching (blended learning, the traditional method).

Table (3): Mean and standard deviations for the experimental and control groups' responses in the areas of scale according to tests.

\begin{tabular}{|c|c|c|c|c|c|}
\hline \multirow{2}{*}{ Areas } & \multirow{2}{*}{ Group } & \multicolumn{2}{|c|}{ Pre-test } & \multicolumn{2}{|c|}{ Post-test } \\
\hline & & *Mean & SD & *Mean & SD \\
\hline \multirow{2}{*}{ Inclination } & control & 3.12 & .67 & 3.24 & .76 \\
\hline & experimental & 3.16 & .98 & 4.37 & .69 \\
\hline \multirow{2}{*}{ Warmth } & control & 3.28 & .73 & 3.33 & .76 \\
\hline & experimental & 3.24 & .77 & 4.29 & .88 \\
\hline \multirow{2}{*}{ Social } & control & 3.31 & .75 & 3.35 & .89 \\
\hline & experimental & 3.28 & .72 & 4.42 & .94 \\
\hline \multirow{2}{*}{ Competence } & control & 3.39 & .60 & 3.32 & .74 \\
\hline & experimental & 3.34 & .67 & 4.47 & .77 \\
\hline \multirow{2}{*}{ Obedience } & control & 3.26 & .98 & 3.22 & .94 \\
\hline & experimental & 3.11 & .73 & 4.18 & .82 \\
\hline \multirow{2}{*}{ Responsibility } & control & 3.36 & .77 & 3.41 & .87 \\
\hline & experimental & 3.30 & .75 & 4.38 & .71 \\
\hline \multirow{2}{*}{ Total } & control & 3.26 & .51 & 3.31 & .64 \\
\hline & experimental & 3.24 & .53 & 4.35 & .55 \\
\hline
\end{tabular}

*The highest degree is(5).

Table (3) shows that there is an apparent variation between the arithmetic averages of the responses of the members of the experimental and control groups, in each of the areas of the scale of learning motivation, according to the variable method of teaching. To find out the levels of statistical significance for these differences, MANCOVAwas used for the scale fields as shown in Table (4).

Table (4): Results of the MANCOVA of differences between the responses of the experimental and control groups on each of the areas of the scale according to the variable method of teaching.

\begin{tabular}{|c|c|c|c|c|c|c|c|}
\hline Source of variance & Areas & SS & DF & MS & F value & Sig & $\begin{array}{l}\text { Effect size } \\
\left(\eta^{2}\right)\end{array}$ \\
\hline \multirow{6}{*}{ Pre-test } & Inclination & 0.661 & 1 & 0.661 & 0.872 & 0.351 & 0.021 \\
\hline & Warmth & 0.524 & 1 & 0.524 & 0.765 & 0.398 & 0.009 \\
\hline & Social & 0.499 & 1 & 0.499 & 0.702 & 0.425 & 0.051 \\
\hline & Competence & 0.605 & 1 & 0.605 & 0.866 & 0.359 & 0.034 \\
\hline & Obedience & 0.511 & 1 & 0.511 & 0.709 & 0.427 & 0.014 \\
\hline & Responsibility & 0.672 & 1 & 0.672 & 1.012 & 0.298 & 0.028 \\
\hline \multirow{6}{*}{$\begin{array}{l}\text { Hotelling =1.994 } \\
\text { Sig=.000 }\end{array}$} & Inclination & 6.389 & 1 & 6.389 & 8.429 & $* 0.001$ & 0.195 \\
\hline & Warmth & 7.622 & 1 & 7.622 & 11.127 & $* 0.001$ & 0.204 \\
\hline & Social & 6.989 & 1 & 6.989 & 9.830 & $* 0.001$ & 0.183 \\
\hline & Competence & 8.254 & 1 & 8.254 & 11.808 & $* 0.001$ & 0.186 \\
\hline & Obedience & 7.564 & 1 & 7.564 & 10.491 & $* 0.001$ & 0.194 \\
\hline & Responsibility & 8.205 & 1 & 8.205 & 12.357 & $* 0.001$ & 0.168 \\
\hline
\end{tabular}




\begin{tabular}{|c|c|c|c|c|c|c|c|}
\hline Source of variance & Areas & SS & DF & MS & F value & Sig & $\begin{array}{l}\text { Effect size } \\
\left(\eta^{2}\right)\end{array}$ \\
\hline \multirow{6}{*}{ Error } & Inclination & 101.572 & 134 & 0.758 & & & \\
\hline & Warmth & 91.79 & 134 & 0.685 & & & \\
\hline & Social & 95.274 & 134 & 0.711 & & & \\
\hline & Competence & 93.666 & 134 & 0.699 & & & \\
\hline & Obedience & 96.614 & 134 & 0.721 & & & \\
\hline & Responsibility & 88.976 & 134 & 0.664 & & & \\
\hline
\end{tabular}

* Statistically significant at the level of significance $(\alpha \leq 0.05)$.

Table (4) shows that there are statistically significant differences at the level of statistical significance $(\alpha \leq$ 0.05 ) between the estimates of the experimental and control groups, on each field of the learning motivation scale due to the effect of the teaching method on all areas of the learning motivation scale, where the differences were In favor of estimates of the experimental group.Table (4) shows that the effect size was $(0.195,0.204,0.183,0.186$, $0.194,0.168$ ) for the teaching method (blended learning ) in the fields of (inclination, warmth, social, competency, obedience, and responsibility) respectively.ANCOVA was used for analyzing the whole areas of the learning motivation scale as shown in Table (5).

Table (5): Results of the ANCOVA for the differences between the estimates of the experimental and control groups on the areas of learning motivation scale as a whole, due to the variable of the teaching method

\begin{tabular}{|l|l||l||l|l|l||l||}
\hline \hline Source of variance & SS & DF & MS & F value & Sig & Size effect \\
\hline \hline Pre-test & 0.925 & 1 & 0.925 & 0.685 & .592 & .014 \\
\hline Method & 12.544 & 1 & 12.544 & 9.285 & $.000^{*}$ & .573 \\
\hline Error & 181.034 & 134 & 1.351 & \multicolumn{2}{|l}{} \\
\hline Total modified & 194.503 & 136 & \multicolumn{3}{|l}{} \\
\cline { 1 - 3 }
\end{tabular}

* Statistically significant at the level of significance $(\alpha \leq 0.05)$.

Table (5) shows that there are statistically significant differences at the level of statistical significance $(\alpha \leq$ 0.05 ) due to the effect of the teaching method on all areas of the learning motivation scale as a whole, and the differences came in favor of the experimental group that was taught according to the blended learning method.

The researchers attribute this effect to increasing students' ability to reconcile between the academic environment and its requirements, increasing their awareness of academic plans and responsibility. They also attributed it to students' preference to work in groups, their interest in using modern methods in learning the academic subjects, and raising their motivation through the diversity of modern technological means and breaking the sense of boredom during the lecture unlike the traditional method of the teaching process (indoctrination), and taking advantage of the capabilities provided by the university to support e-learning (distance learning), which enhances and develops students 'motivation to use e-learning methods in studying.

It is also due to the interest of Jadara University in providing the university with all that is new at the academic level from e-learning systems to evaluate the distance learning outcomes for students at the university and linking them to the efficiency of students and their ability to produce knowledge and learning, and the diversity of methods of measurement and evaluation, which provokes students' internal motivation to present ideas New and creative and presented in a new interesting way, which makes students more effective and able to accomplish all of the tasks, and their feeling that the majority of their university courses have become useful and meaningful, and the desire to inquire about any ambiguity to study and to do all the requirements. This result is consistent with the results the study of (Al-Nqithan, 2009), (Nehme, 2010), and (Kim \& Frick, 2011) which indicated that it is possible to obtain motivated students by creating educational environments based on using electronic learning methods and thus access to effective learning.

\section{Recommendations}

Considering the results of the current study, the researcher recommended the following:

1 .Using the blended learning program in the process of teaching psychological subjects in universities.

2. Holding training courses for academic staff to enable them to properly prepare for e-learning, develop their abilities and skills in employing them in educational situations under the supervision of specialists to introduce them to how to design and build and implement teaching and e-learning strategies and tools.

3. Emphasizing the importance of incorporating teaching, and e-learning strategies, and tools into the educational process, applying them in the educational process, and increasing the awareness of academic staff in employing them in their classroom and educational situations.

4.Designing training programs for all aspects of the educational process to achieve performance, and higher-order 
thinking skills, spreading the culture of e-learning and obtaining its positive benefits for both the learner and the educational institution.

5.Clarify how to work on the use of multiple strategies in the stage of university education through cooperation and integrated coordination between specialists and parties to the learning process. Adopting integrated strategies in evaluating the educational process, which contribute effectively to improving the level and quantity of information students receive, selecting the most appropriate evaluation tools, and assisting them in the process of analyzing information and writing reports.

6.Encouraging the academic staff to use new teaching methods such as information technology, using effective elearning methods in the educational process.

7.Encouraging students to use strategies and tools for computerized (electronic) learning that increase their activity and intellectual development.

8.Providing resources and making them accessible to all students by using computer technologies and the Internet, encouraging students to participate in extra-curricular activities that generate self-confidence and raise their ability to communicate more effectively with one another. Accordingly, we can build a corporation between the teacher and the student and provide an attractive environment for students.

\section{References}

AL-Jabri, N. (2011) Attitudes of University Students and Professors towards E-Learning, Childhood and Education Journal, Sixth Issue, Third Year, January, Alexandria University.

Al-Issawi, S. T. (2011) The Concept of Motivation, College of Basic Education, Babil, Iraq.http://www.uobabylon.edu.iq/uobColeges/service showarticle.aspx?fid=11\&pubid=2716

Al-Shannaq, Q,. and Bani Domi, H. (2010), Attitudes of teachers and students towards the use of e-learning in Jordanian secondary schools, Damascus University Journal, Volume 65 - No. 2 + 1, p. 235.

Al-Nqithan, I. (2009), Attitudes of students towards the use of technology in university teaching, symposium on developing faculty members in university education institutions, Riyadh.

Miqdad, M. (2010), Motivation for Education among E-Learning Students, E-Learning Conference in Promoting Knowledge Societies, Bahrain.

Barolli, L., Koyama, A., Durresi, A., \& De Marco, G. (2006). A web-based e-learning system for increasing study efficiency by stimulating learner's motivation. Information Systems Frontiers, 8(4), 297-306.

Brophy, J. E. (2010). Motivating students to learn: Taylor \& Francis

Gebara, T. (2010). Comparing A Blended Learning Environment To A Distance Learning Environment For Teaching A Learning And Motivation Strategies Course. The Ohio State University.

Ghergulescu, I., \& Muntean, C. H. (2010). MoGAME: Motivation based Game Level Adaptation Mechanism.

Ghergulescu, I., \& Muntean, C. H. (2011). Supporting Motivation Based Educational Games Through Web 3.0. Towards Learning and Instruction in Web 3.0: Advances in Cognitive and Educational Psychology, 247.

Ghergulescu, I., \& Muntean, C. H. (2010). Supporting ASSESSMENT OF MOTIVATION IN GAMING BASED ELEARNING: IADIS International Conference on Cognition and Exploratory Learning in Digital Age (CELDA 2010).

Hartnett, M., St George, A., \& Dron, J. (2011). Being together-factors that unintentionally undermine motivation. Journal of Open, Flexible and Distance Learning, 15(1), 1-16.

Hartnett, M., St George, A., \& Dron, J. (2011). Examining motivation in online distance learning environments: Complex, multifaceted and situation-dependent. The International Review of Research in Open and Distance Learning, 12(6), 20-38.

Keller, J. M. (2008). First principles of motivation to learn and e3-learning. Distance Education, 29(2), 175-185.

Kim, K. J., \& Frick, T. W. (2011). Changes in student motivation during online learning. Journal of Educational Computing Research, 44(1), 1-23.

Nehme, M. (2010). E-LEARNING AND STUDENTS'MOTIVATION. Legal Education Review, 20(1/2), 223.

Tuckman, B. W., \& Kennedy, G. (2009). Teaching learning and motivation strategies to enhance the success of firstterm college students. American Educational Research Association, San Diego, CA.

Wu, W., \& Hwang, L. Y. (2010). The effectiveness of e-learning for blended courses in colleges: A Multi-Level Empirical Study. 